\title{
PSYCHO-SOCIAL LEARNING ENVIRONMENT IN ELEMENTRAY CLASSROOMS AND ITS RELATIONSHIP WITH STUDENTS' ACADEMIC ACHIEVEMENT
}

\author{
Saima Iram ${ }^{*}$ \\ Munazza Ambreen ${ }^{* *}$
}

\begin{abstract}
Teaching learning process, being complex, social, dynamic and interactive in its nature, is prone to be affected by the psycho-social learning environment present in the classrooms. This study was conducted to explore the prevailing psycho-social learning environment and its relationship with students' academic achievement at elementary level in District Attock. The population consisted of all the elementary teachers of Mathematics for $7^{\text {th }}$ Graders of public schools in all six sub districts of District Attock. Three sub districts (Jund, Hassan Abdal, and Pindi Gheb) were selected through cluster sampling technique. Two hundred and twelve mathematics elementary teachers were included in the sample. For observation, purposive sample was further delimited to $25 \%$ of the sample of the study. Thus, classrooms of 53 teachers were observed. An observation sheet based on three scales of 'What Is Happening in the Class?'(WIHIC) questionnaire was used for data collection, while academic achievement of $7^{\text {th }}$ graders was assessed through the marks of quarterly exams. Collected data were analyzed through SPSS by mean score while Pearson " $r$ " was used to find the relationship between psychosocial environment and academic achievement and standardized regression weights " $\beta$ " was also applied to find the effect of psychosocial environment on academic achievement. The findings revealed that most of the elementary classrooms were psychosocially desirable and were found to be Task oriented and Cooperative while Involvement was also found significant at elementary level. Positive and significant relationship between psychosocial learning environment and academic achievement was also found.
\end{abstract}

Keywords: Psychosocial, learning environment, academic achievement

\footnotetext{
* M.Phil Scholar, Faculty of Education, Allama Iqbal Open University (AIOU), Islamabad, Pakistan

${ }^{* *}$ Assistant Professor, Faculty of Education, (AIOU), Islamabad, Pakistan
} 


\section{Introduction}

The era we are living in, is characterized by incredible advancements and profound changes in all fields of life. Evolution of Information and Communication Technology (ICT) has brought a revolution in the world. It has not only turned the world into a global village but has given birth to knowledge- driven economy. Advancements of this era are, in fact, accompanied by numerous challenges, complex problems and novel issues. Globalization has resulted in increased competitiveness in all sectors of life and knowledge- driven economy has resulted in increased dependence of socio-economic development upon the knowledge and skills of the members of the society. These factors resulted in an ever increased focus towards the quality of education at all levels (Ambreen, 2012). In this present era it has become inevitable for policy makers and practitioners of education to re-examine quality of educational services, redefine educational policies and practices and to measure, continuously, satisfaction level of their customers. Though quality was and will always be very important for the institutions of education, like all the other organizations, but its significance in present era has become crystal clear as discussed by Newton (2007) cited in Ambreen (2012):

"The concept of quality is not new: it has always been part of the academic tradition. It is the outside world that now emphasizes the need for attention to quality (p.14)."

Aly (2007) pointed out five pillars of quality in education, these are: Curriculum, text books, assessment, teachers and learning environment. Among all the other factors, learning environment is the most important pillar as it decides the quality of teaching and learning process. McCloud (2005) contends that in a supportive environment teachers have more time to focus on their teaching while students function best in 'classrooms that are perceived as safe, warm, supportive, nonthreatening and socially supportive' (Laroque, 2008, p 28). Laroque (2008) believes that in order to accelerate learning where a balanced teaching process is required, it is also inevitable that students are provided with environment that is socially balanced.

Though the significance of learning environment has been well established, very little research has been done to actually observe the nature of psychosocial environment present in classrooms. The relationship of psychosocial learning environment and students' academic achievement was rarely explored by the researchers. The present study seems to be the first one in Pakistani context at elementary level. 
The main objectives of the study were i) to explore the nature of existing psychosocial learning environment of the classrooms at elementary level and ii) to find out the relationship (if it exists) between psychosocial learning environment and students' academic achievement.

$\mathrm{H}_{0}$ : There is no significant relationship between classroom learning environment and students' academic achievement.

\section{Literature Review}

In order to situate this study and find out its significance in the broader context of literature, a review of the selected literature from different researches is presented in this chapter. Review of related literature includes definitions and explanations of key concepts used in the research. The major concepts used in this research are psychosocial learning environment and students' academic achievement.

\section{Psychosocial Learning Environment}

As a behavioral background, classrooms run on interactions between and among participants. Students become more motivated and connected to teachers and peers, when they begin to demonstrate positive route of development in both social and academic areas.

Learning without a supportive and desirable psycho-social environment cannot be ensured. Johnson and Johnson (2009) argued that desirable and comparatively permanent change in behaviour that is called learning occurs only when a web of social links cooperates formally and informally. Similarly according to Tanner, (2000) learning environment refers to the establishment of a caring and relevant learning community that provides support to all learners in achieving learning goals up to their highest potential. Luo, Huang and Najjar (2007) agreed to the views of Tanner (2000) when they believe that learning environment can be defined as the social perspective, pedagogical and psychological which can affect attitudes, learning and achievement of the students. Psychosocially supportive classrooms are those where teachers are sensitive to student's needs, teacher student needs are warm, respectful and friendly, and active involvement of students is encouraged (Rudasill, Gallagher, \& White, 2010).

Sandberg (1998) describes that teaching and learning environment should focus on six functions: collaborate, inform, produce, communicate, support, and manage. It represents the whole mixture of 
components and activities within which learning takes place. Emotionally supportive classrooms are related to greater student motivation, interest, enjoyment, and engagement, less violent behaviour, greater school adjustment and academic achievement. (Curby et al, 2009; Pianta, Belsky, Vandergrift, Houts, \& Morrison, 2008; Rudasill, Gallagher \& White, 2010).

Gardiner (1989) presented a model of a learning environment in which three overlapping circles described as ecosfera (physical environment), sociosfera (psychosocial environment) and tecnosfera (artificial learning environment). According to Gardiner, students are the most complex component in the process of learning and they are influenced by the physical and psychosocial aspects of the learning environment.

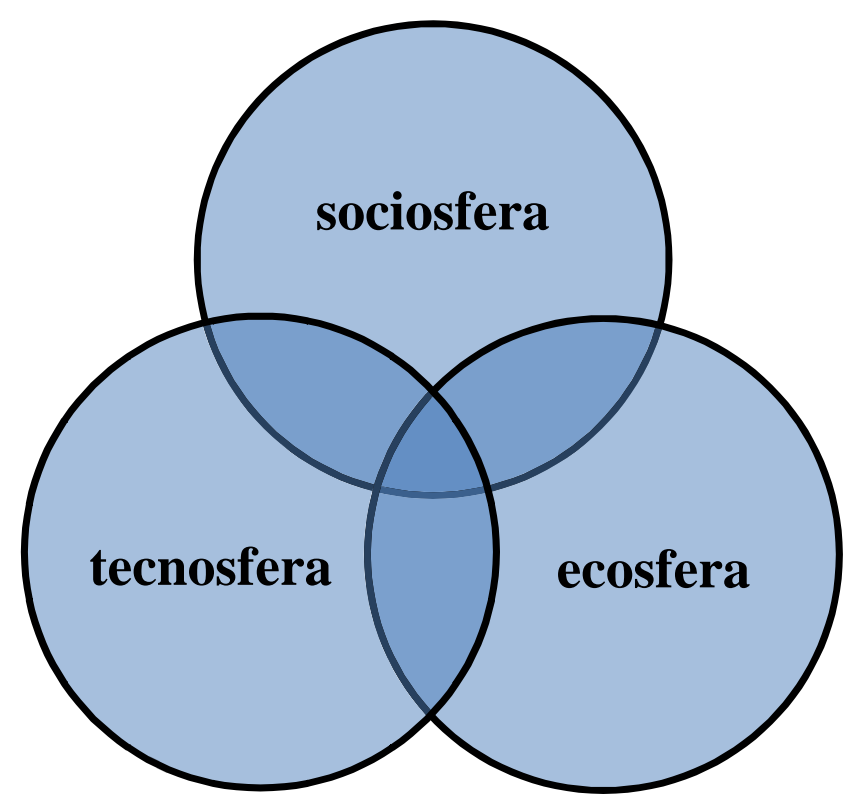

Figure 1. Model of Learning Environment

Source: Gardiner's (1989) Model with the Classroom Physical and Psychosocial Environment.

Zandvliet (1999) modified Gardiner's (1989) model of learning environment. He divided it in two components that are physical and 
psychological environment with each of them having different critical factors.

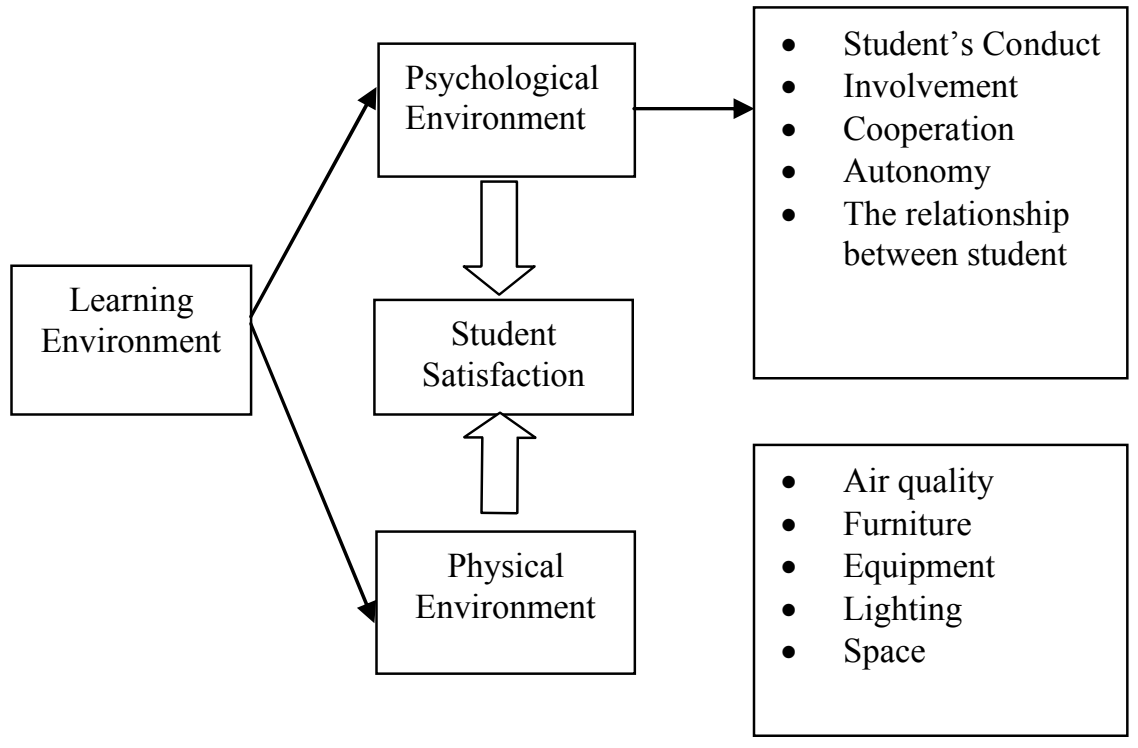

Figure 2. Model of Psychosocial and Physical Learning Environment

Source: Zandvliet (1999) modified Gardiner's (1989) model

Hamre \& Pianta (2007) describes that the quality of social and emotional interactions in a classroom between and among students. What is Happening in This Class? (WIHIC) is an important instrument frequently used to assess classroom learning environment. It is a combination of different classroom learning environment measuring instruments. Original version of WIHIC consisted of ninety items with nine subscales but later on it was improved and now the final form of WIHIC comprised of seven scales, each of them having eight items. These are Student Cohesiveness, Teacher Support, Involvement, Investigation, Task Orientation, Cooperation and Equity. MeCleod and Fraser (2010) applied Arabic Translation of what is Happening in This Class (WIHIC) questionnaire for Arabic countries, Korian version of WIHIC has also been cross validated in Korea while cross cultural validity of WIHIC was also confirmed through the study of Kim (2000).For measuring psychosocial learning environment, frame work of three subscales of WIHIC was used. So subscales of WIHIC are described in detail. 


\section{Student Cohesiveness}

It is very easy to recognize "cohesiveness" but difficult to define it as a term. It is a safeguarding variable of group that can be understand intuitively. Cohesive groups have several positive qualities like a general perception of "we-ness", feeling of friendship and loyalty among group members and high morale."Student" is an individual, registered at any institution while classroom psychosocial environment is instrumental to student cohesiveness (Hamre \& Pianta, 2007).

\section{Teacher Support}

Teachers need to focus on how to accommodate their students in the best way with learning and emotional support. When they take personal interest to help students, this improves their mutual relationships but improving students' relationships with their teachers will not produce gain in achievement. Students don't always follow the same procedure of classroom as they are emotionally different. Some students are overly energetic or aggressive and they are difficult to handle. They often don't "play by the same rules" or they don't adjust their behaviour (Russell, Ainley \& Frydenberg, 2005). Teachers can help these students to accommodate in the class with peers by acknowledging their contribution to a class discussion (Russell, Ainley \& Frydenberg, 2005).

\section{Involvement}

Positive student involvement has been associated with concepts including participation, motivation, energy, action, direction, connection (Russell, Ainley \& Frydenberg, 2005), autonomy, belonging, competence, effort, persistence, attention, interest and investment (Fullarton, 2002) while disengagement, on the other hand, has been associated with concepts including drifting apart, objectivity, disintegration, segregation, weakness, insignificance, disconnectedness and boredom (Appleton et al., 2008). Students take an active role in building new knowledge. When students perceive learning tasks as useful and important, they will use active learning strategies to integrate their existing knowledge with new experience and will actively engage in the learning tasks. When students do not perceive the value of learning tasks, they use surface learning strategies (such as memorization) to learn (Brophy 1998; Marks, 2001).

\section{Investigation}

Investigation is the degree to which the importance is given to the process of inquiry, skills and their use in problem solving. The approach of investigation is used in teaching to increase intellectual engagement 
and deep understanding. The complex and interconnected nature of knowledge provide opportunities for both teachers and students to work collaboratively. Investigation starts when teachers engage students to strive to nurture deep thinking, not merely 'having students involved in tasks' rather it involves learners to carry out investigation to test ideas, explain the meaning of statements, develop deep understanding of content knowledge, allow students to investigate his/her questions while ask them to think about statements and encouraging the child to try again. Memorizing facts and information is not so important than generation and transmission of knowledge. This is why teachers must change from a focus on "what we know" to an emphasis on "how we come to know" (Marks, 2000).

\section{Task Orientation:}

The "Task Orientation" realm covers the ability to organize oneself around the given tasks and the ability to control one's behaviour to perform the task accordingly. It includes all the steps teacher needs to take to foster student involvement in the task and to establish a productive working environment. Engagement within Tasks measures the degree to which the child remains focused on any given task. SelfReliance includes taking learning into one's own hands and the ability to seek opportunities rather than passively waiting for teacher's direction and making best use of classroom resources including the teacher. Behavior Control measures the degree to which the child controls movement, attitude, physical actions and expressions to make match to the expectations of the settings and teachers. They actually develop the sense that what is expected of them in the task (Hamre\&Pianta2007).

\section{Cooperation}

Cooperation is based on the socially controlled transform of information between learners. Cooperation in groups allows students to put collective effort in which each learner is motivated to increase the learning and held accountable for his or her own learning. Johnson and Johnson (2009) defined the small group cooperative learning as "classroom environment where students interact with each other in small groups while working together on academic task to attain the common goal".

Parkar (2008) briefly defined cooperation and cooperative learning as "Cooperative means working together to accomplish shared goals 
while cooperative learning is instructional use of small groups so that students work together to maximize each other's learning".

Cooperation involves joint operation or action and it also has economic and social interpretation such as i) the social meaning of cooperation is an activity shared for mutual benefits, ii) the economic cooperation is a joint effort for the purpose of production, purchase and distribution and collaboration means to work together with one or few others in a project such as research.

\section{Equity}

Equity is an effective way, condition, inclusive and respectful treatment to people considering their individual differences. It is a part of good teaching because teachers want their students to excel and usually very amenable to fine-tuning the sensitivities of their students behaviour but may not be aware of all of the ways they can help them. When the issues of equity are raised with empathy and helpfulness, teachers are to grab opportunities to reach more of their students having more of the time. There are two dimensions in equity in classroom; first is fairness which means making sure that the personal and social circumstances (gender, socio-economic status or ethnic origin) should not be an obstacle to achieving educational potential. Fairness means giving students what they need and providing them with equal chance to participate in learning activities. A productive classroom environment can be formed, when teachers truly listen to students and respect their ideas. Second is inclusion that means setting a basic minimum standard for all i.e., everyone should be able to read, write and do simple arithmetic.

A study of associations of students' perception about their classroom learning environment with their satisfaction towards Mathematics in Brunei Darussalam is conducted by Majeed, Fraser \& Aldrigds in 2002. They found a positive students' perception about their psychosocial Mathematic classroom learning environment. Positive significant associations of students' perception about their mathematics classroom learning environment with their satisfaction towards Mathematics are also showed. As Marks (2001) states that unless students experience a positive and supportive psychosocial environment, some may never achieve the most minimum standards or realize their full potential.

Brackett, Reyes, Susan, Elbertson and Salovey (2011) conducted a study, "Classroom Emotional Climate, Teacher Affiliation, and Student Conduct". In this study they tested whether students' perceptions of their relationships with their teachers, referred to as teacher affiliation, mediated the association between observed CEC and student conduct. Observations 
and report card grades collected from fifth- and sixth-grade classrooms showed a positive relationship between CEC and student conduct that was mediated by teacher affiliation, suggesting that in these emotionally supportive classrooms, students liked and respected their teachers more and, in turn, behaved better. These findings are aligned with a growing body of research, evidencing the influence of emotional aspects of the classroom in student motivation, engagement, performance, and conduct in school (e.g., Battistich, Schaps, \& Wilson, 2004; Brock et al., 2008; Curby et al., 2009; Pianta et al., 2008; Kosir, Socan, \&Pecjak, 2007).

Afari (2015) conducted a survey study entitled as 'The Effects of Psychosocial Learning Environment on Students' Attitudes towards Mathematics' on the three aspects of Psychosocial Learning Environment i.e. Teacher Support, Involvement, and Task orientation. Researcher used the adapted version of WIHIC questionnaire to measure classroom learning environment and Test of Mathematics Related Attitudes (TOMRA). The findings of this study suggest that the two aspects of learning environment (teacher support and personal relevance) significantly influence students' enjoyment of mathematics lessons and academic self-efficacy and achievement.

Islam (2011) conducted a survey 'Impact of students' perceptions about teacher interaction and classroom learning environment on attitude towards mathematics and achievement". To measure classroom learning environment WIHIC scale was used, attitude towards mathematics was measured by QOMRA and student's perception about teacher interaction were measured by QTI. Results of the study revealed that among the seven subscales of classroom learning environment, task orientation and equity were the classrooms learning environment predictors of students' attitude towards mathematics. Mathematics classrooms in Punjab province are student cohesive, task oriented and equity based while students' involvement in classrooms is found casual.

Though the significance of learning environment has been well established and sufficient literature is available in this context. Very little research has been done to actually observe the nature of psychosocial environment present in classrooms. The relationship of psychosocial learning environment and students' academic achievement was rarely explored by the researchers. The present study seems to be the first one in Pakistani context and at elementary level.

\section{Methodology}

Complete account of the sample selection, the process of instrumentation, data collection and the methods applied in order to analyse the data are also included in this chapter. 


\section{Research Design}

The target population comprised of all the mathematics elementary teachers of public schools in all the six sub districts of District Attock and all the $7^{\text {th }}$ graders studying in the intact classes of these teachers. Four hundred and forty two (218 male and 224 female) mathematics elementary teachers and $7^{\text {th }}$ graders of public schools in District Attock comprised the population. This study was focusing on the observation of psycho-social learning environment of the classroom for a full class period. As the nature of the study involved observation of psychosocial learning environment of the classrooms, it was not feasible for the researcher to observe classrooms of 212 mathematics elementary teachers. Hence, for observation purposive sample was further delimited to $25 \%$ of the total sample. Thus 53 ( 25 male and 28 female) teachers were selected randomly as sample for observation.

Table 1

Brief description of Sample for Observation

\begin{tabular}{lllllll}
\hline Sub Districts & \multicolumn{3}{l}{ No. of } & Mathematics Teachers & \multicolumn{3}{c}{ No. of $7^{\text {th }}$ Graders } \\
\cline { 2 - 7 } & Male & Female & Total & Male & Female & Total \\
\hline Attock & 9 & 10 & 19 & 351 & 416 & 767 \\
Jund & 8 & 9 & 17 & 340 & 384 & 724 \\
Hassan Abdal & 8 & 9 & 17 & 334 & 352 & 686 \\
Total & 25 & 28 & 53 & 1025 & 1152 & 2177 \\
\hline
\end{tabular}

Table 1 indicates brief description of sample for observation. Hence 25 male \& 28 female mathematics elementary teachers were selected from Attock, Jund and Hassan Abdal sub-districts respectively for study.

\section{Instruments}

Observation schedule was developed at semantic differential scale, ranging from Desirable to Undesirable consisting of 15 items. Each scale consisted of five (05) items. The scale was converted into five point likert scale $1=$ Undesirable, $2=$ Somewhat Undesirable, $3=$ Neither, $4=$ Somewhat desirable, and 5= Desirable. After the proper consultation of supervisor, the tool was given to some experts for validation. Construct validity of the items was also ensured through empirical evidences regarding the indicators belonging to certain psychosocial learning environment scale. In the light of valuable suggestions and comments of experts, few changes were made. 
The Task Orientation scale assesses the extent to which the students were ready to start the class. It also exhibits that the knowledge of students about task is fostered when they know the goal of the lesson and their prior knowledge is activated.

The Involvement scale assesses the extent to which students are involved in the classrooms and it also indicated that students' involvement is enhanced when they are participating in discussions and have attentive interest in what is happening in the classroom. It also exhibits that teacher plays an important part in helping students to understand what they are learning (Taylor \& Campbell-Williams, 1993).

The Cooperation scale assesses the extent to which the teachers is friendly with his students which is integral to the student's success and creating a cooperative learning environment (Hijzen, Boekaerts, $\&$ Vedder, 2007). Cooperation of the classroom is tremendous when teachers give students time to respond and make sure positive interdependence among group members.

\section{Validity and Reliability}

Wragg (2002) concluded that definitely there are many difficulties in visiting the classrooms and observing the lesson but it is an outstanding and an effective way to gain firsthand information of classroom activities. The psychosocial measures of this study were obtained by administering three scales (Task Orientation, Involvement, and Cooperation), selected and adapted from a learning environment instrument: What is Happening in This Classroom (WIHIC; Fraser et al, 1996; 1998a, b). Researcher chose WIHIC because it has consistently been found to be more reliable, valid and useful in numerous studies in various subject areas at various grade levels in Asian, British and Australian classrooms (Aldridge, Fraser \&Ntuli, 2000; Dorman, 2002).

The observation schedule was administered to 10 teachers for pilot testing, member of same population but excluded from the sample. As the relationship of instructional strategies and classroom learning environment was to observe, so observation was conducted on 10 randomly selected teachers from the same sample of questionnaire from pilot testing. The items analysis was performed. The Means and alpha reliability coefficient of subscales were also calculated and reported in table 2 . 
Table 2

Mean and Alpha Reliability Coefficient of Psychosocial Learning Environment and Subscales

\begin{tabular}{lcc}
\hline & Mean & $\begin{array}{c}\text { Cronbach Alpha } \\
\text { Reliability }\end{array}$ \\
\hline Psychosocial Learning Environment & 4.0 & .89 \\
i. Task Orientation & 4.0 & .89 \\
ii. Involvement & 3.6 & .88 \\
iii. Cooperation & 4.0 & .90 \\
\hline
\end{tabular}

The internal consistency (Cronbach's alpha) of the Task Orientation scale was 0.89 , considered as an internally reliable scale. The internal consistency (Cronbach's alpha) of the Involvement scale was 0.88 , also considered as an internally reliable scale while the internal consistency (Cronbach's alpha) of the Cooperation scale was 0.90which was also considered an internally reliable scale.

The value of Cronbach Alpha reliability " $\alpha$ " for psychosocial learning environment scale was 0.89. As per De Villis (2007), the acceptable value of reliability is 0.5 so scale for observation of psychosocial learning environment was found reliable.

\section{Data Collection}

In order to collect data for the analysis of psychosocial learning environment, following observation procedure was adopted

1. One male teacher was trained as an observer for the present study as it was difficult for researcher to observe male teachers.

2. Debriefing session was organized in which all the important aspects of procedure such as duration of observation and recording were discussed.

3. The observer spent 3-5 minutes in class in order to get used to the classroom environment.

4. The observer started recording observation on the observation sheet.

5. Observation was recorded after every 5 seconds.

6. The observers spent 5-10 minutes in each class in order to get used to the classroom environment then they started coding observations on 
the observation sheet. In each class of 35-40 minutes, at least 25 minutes were used for observation.

It was second term of the classes and after a month, second term exams were going to be held, so the teachers were asked to provide results of students in the subject of mathematics after the completion of examination process. Inter coder and intra coder reliability

In order to maintain inter coder and intra coder reliability both observers met after every 3 days to discuss the procedure, experiences, perceptions understanding of coding the observation. This minimize the lower inter coder reliability.

\section{Data Analysis}

Data collected for the study were analysed with the use of Statistical Package for Social Sciences (SPSS) version 16. Data were analysed to find out reliability of the observational sheet. Observation sheet was developed by keeping in view psycho-social dimension of learning environment comprised of 3 subscales (Task Orientation, Involvement and Cooperation). Observation sheet was developed at semantic differential scale; 5. Desirable- 4. Somewhat desirable, 3. Neither2. Somewhat undesirable, 1. Undesirable

To determine the relationship whether exist or not between learning environment and students' academic achievement, Pearson correlation coefficient and multiple regression were calculated. Pearson correlation "r" was used to explain bivariate relationship between psychosocial learning environment and students' academic achievement and standardized regression value was calculated to find out which factor of psychosocial learning environment was predictor of academic achievement.

Table 3

Mean of Components of Psychosocial Learning Environment

\begin{tabular}{lc}
\hline Psychosocial Learning Environment & Mean \\
\hline Task Orientation & 3.8 \\
Involvement & 3.7 \\
Cooperation & 4.0 \\
\hline
\end{tabular}

Table 3 reflects that Task orientation, Involvement and Cooperation were the favorable aspects of classroom learning environment with mean scores $(3.8,3.7 \& 4.0)$. 
$\mathbf{H}_{\mathbf{0}}$ : There is no significant relationship between psychosocial learning environment and students' Academic Achievement.

\section{Relationship between learning Environment and students' Academic Achievement}

Table 4

Simple Correlation " $r$ " and Standardised Beta Weights " $\beta$ " between Subscales of Psychosocial Learning Environment and Academic Achievement

\begin{tabular}{lllll}
\hline & \multicolumn{4}{l}{ Academic Achievement } \\
\cline { 2 - 5 } & $\mathrm{r}$ & sig. & $\beta$ & sig. \\
\hline Task Orientation & $.735^{* *}$ & .000 & $.735^{* *}$ & .000 \\
Involvement & $.855^{* *}$ & .000 & $.855^{* *}$ & .000 \\
Cooperation & $.812^{* *}$ & .000 & $.812^{* *}$ & .000 \\
\hline
\end{tabular}

$\mathrm{N}=53, \mathrm{p}<0.01$

Table 4 shows that there exist a positive correlation between learning environment and students' academic achievement. The value $r=.735^{* *}$, $\mathrm{r}=.855^{* *}, \mathrm{r}=.812^{* *}$ at $\mathrm{p}<0.01$ for Task Orientation, Involvement and Cooperation respectively shows positive and significant relationship with academic achievement. It indicates that the environment which is equipped with task orientation, involvement and cooperation effect academic achievement of students. Standardized Beta weights $\left(\beta=.735^{* *}\right.$, $\beta=.855^{* *}, \beta=.812^{* *}$ atp $\left.<0.01\right)$ proposed that Task Orientation, Cooperation and Involvement are contributing significantly in explaining academic achievement of students. This revealed that learning environment have significant impact on students' achievement.

Table 5

Simple Correlation " $r$ " and Standardized Regression Weights " $\beta$ " between Learning Environment and Academic Achievement

\begin{tabular}{lllll}
\hline & \multicolumn{4}{l}{ Academic Achievement } \\
\cline { 2 - 5 } & $\mathrm{r}$ & sig. & $\beta$ & sig. \\
\hline Learning Environment & $.599^{* *}$ & .000 & $.599^{* *}$ & .000 \\
\hline $\mathrm{N}=53, \mathrm{p}<0.01$ & & & &
\end{tabular}

Table 5shows that there exist a positive and significant relationship between learning environment and academic achievement having $\mathrm{r}=.599^{* *}$ at $\mathrm{p}<0.01$ level. The standardized Beta weights $\left(\beta=.599^{* * *}\right.$ at 
$\mathrm{p}<0.01)$ proposed that students perform better academically when their environment is psychosocially supportive.

Hence the null Hypothesis $\left(\mathrm{H}_{0}\right)$ "There is no significant relationship between classroom learning environment and students' academic achievement" is rejected. Thus it is concluded that there is found a positive and significant relationship between classroom learning environment and students' academic achievement.

\section{Results}

1. Mean value 3.8, 3.7, 4.0 revealed that Task Orientation, Involvement and Cooperation were observed desirable in the most of the Mathematics classrooms (Table 3).

2. Positive and significant influence is found between three factors of psychosocial learning environment on students' academic achievement. It is found that Task Orientation, Involvement and Cooperation is contributing positively and significantly in academic achievement with $\mathrm{r}=.735^{* *}, \mathrm{r}=.855^{* *}, \mathrm{r}=.812^{* *}$ and $\beta=.735^{* *}$, $\beta=.855^{* *}, \beta=.812^{* *}$ significant at $p<0.01$ (Table 4).

3. Three factors (Task Orientation, Involvement and Cooperation) of Psycho social learning environment cumulatively are positively and significantly correlated with students' academic achievement with $\mathrm{r}=.599^{* *}, \beta=.599^{* *}$ at $\mathrm{p}<0.01$. It proposed that students' academic achievement enhances when their learning environment is psychosocially supportive (Table 5).

\section{Discussion}

The purpose of the study was to examine relationship between three aspects of psychosocial learning environment. The findings suggested that psychosocial learning environment contributes in academic achievement of students. The researcher faced many problems during the study specially getting access to the classrooms for conducting observations but the teachers included in the sample were very cooperative for the provision of chance to the researcher to gain firsthand knowledge. As a result this study turned into a successful endeavour to explain the contribution of teaching strategies in enhancing classroom learning environment and academic achievement. It was an encouraging fact that teachers included in the sample remained confident, sustained almost with the same methodologies and with the same speed. During the informal sittings with the researcher, they exchange their ideas about their teaching. They were of the view that, their teaching may not be so bookish but still it produces good results. 
Samph (1996) installed microphone in his classrooms and also sent observers either announced or unannounced some time later. He further found that teachers asked more questions, appreciated students more and involved them more in classroom discussion when an observer was present. The behavior of the teachers and students may differ accordingly in the presence of observer. They may behave differently than normal in the presence of an outsider (Wragg, 2002). Therefore the observers studied at least two lessons instead of only a single lesson. Hence the researchers in this study started visiting the classes before the start of recording the observation. Further, the data was collected from two lessons of each teacher of the sample.

During a crucial period of social and emotional development, schools and classrooms are the child's environment for supporting and enriching his developmental needs. A growing body of research emphasizes on improvement of learning environment as the need for a shift in the focus of education. However, it was apparent to both researchers and educators alike that emotions are dominant to learning within the classroom.

This study revealed that a classroom environment which is task oriented yields better results. Involvement of the classrooms also contributes in improving students' achievement. The more the students focus on their lessons, the more their achievement increases. Similarly classroom cooperation in which teachers give students time to respond and develop positive interactions with the student supports their achievement. This study revealed that three aspects (Task Orientation, Involvement and Cooperation) of psychosocial learning environment in the mathematics classrooms are positively correlated with academic achievement of the students in the mathematics. The results of the study in hand are supported by previous studies (Islam, 2011, Afari, 2015; Lujan, 1998).

Learning environment is significantly and positively correlated with academic achievement of students at elementary level and is a strong predictor of academic achievement. It verifies Islam (2011) claim that learning environment had a strong relationship with students' achievement. The findings of the study support the previous studies (Lippman (2007).

The results of my study have the potential to influence educators and policymakers to focus on stimulating a number of learning environment elements, such as teaching methods that involve cooperative work, active participation in the learning process and an atmosphere in which all students will perceive their teachers as supportive and approachable which will hopefully increase students involvement in their lessons and improve their achievement in academic competence. 
There are many noteworthy findings in this study while analyzing this study critically, some limitations were also found. First point is that, as with mostly survey studies, data for classroom learning environment was collected through a single source; observation, this indicates that the present study might represent a specific situation in time. The generalization of the results to other populations should be made with caution since this study involved only one district Attock (212 mathematics elementary teachers), while for observational purpose the sample was further delimited to $25 \%$ (53) of the teachers.

\section{Conclusions}

1. Majority of the mathematics classrooms of District Attock were observed psychosocially desirable places as most of them were task oriented while Involvement and Cooperation were also observed in the learning environment of the classroom of District Attock.

2. Classrooms that are supported with Task Orientation, Involvement and Cooperation yield good results in mathematics.

3. Classroom learning environments rated with objective indicators to be psychosocially supportive had a positive impact on students' academic achievement.

\section{REFERENCES}

Afari, E. (2015). The Effects of Psychosocial Learning Environment on Students' Attitudes Towards Mathematics. Application of Structural Equation Modeling in Educational Research and Practice. Contemporary Approaches to Research in Learning Innovations, 91-114.

Aldridge, J. M., Fraser, B.J., \& Ntuli, S. (2009). Utilising learning environment assessments to improve teaching practices among in-service teachers undertaking a distance-education programme. South African Journal of Education, 29, 147-170.

Aly, J.H. (2007). Education in Pakistan: A white paper, Retrieved September 2014, from http://www.Safedafed.org/document/PDF/WhitePaper/20on/\%20 Education\%2policy.pd

Ambreen, M. (2012). Impact of Communication Climate and Managerial Communication Styles upon Quality Assurance in Higher Education in Pakistan. Unpublished doctoral Thesis, submitted to National University of Modern Languages, Islamabad. Pakistan. 
Appleton, J. J., Christenson, S. L., \& Furlong, M. J. (2008).Student engagement with school: Critical conceptual and methodological issues of the construct. Psychology in the Schools, 45, 369-386.Australian Youth (LSAY), viewed 14 June, 2006.

Battistich, V., Schaps, E., \& Wilson, N. (2008). Effects of an Elementary School Intervention on Students' "Connectedness" to School and Social Adjustment During Middle School. Journal of Primary Prevention. 2004;24:243-262.

Brackett, M. A., Reyes, M. R., Susan E. R., Elbertson, N. A., Salovey, P. (2011). Classroom Emotional Climate, Teacher Affiliation and Student Conduct, Journal of Classroom Interaction, ISSN 0749-4025, Vol. 46.1, pages 27-36.

Brophy, J. (1998). Motivating students to learn (2nd ed.). Boston, MA: McGraw-Hill.

Curby, T., LoCasale-Crouch, J., Konold, T., Pianta, R., Howes, C., Burkina, M., Barbarin, O. (2009).The relations of observed pre-K classroom quality profiles to children's achievement and social competence. Early Education and Development, 20, 346-372.

De Villis, R. F. (2007). Scale development: Theory and Application. Newbury park: Sage Publications.

Dorman, J. P. (2002) Cross national validation of the What Is Happening In this Class questionnaire using confirmatory factor analysis. Learning Environments Research, 6, 231-245.

Environment? CELE Exchange, Centre for Effective Learning Environments from OECD Publishing. http://EconPapers.repec.org/RePEc:oec:eduaac: 2010/13-en

Fraser, B. J. (1996). Research on Classroom and Social Climate. In D. Gabel (Ed.) Handbook of research on science teaching and learning (p 493-541). New York: Macmillan.

Fraser, B. J. (1998a). Science Learning Environments: Assessments, Effects and Determinants. In B. J. Fraser \& K. G. Tobin (Eds.), International handbook of science education (pp. 527-564). Dordrecht, The Netherlands: Kluwer.

Fullarton, S., (2002). Student Engagement with School: Individual and Schoollevel.

Gardiner, W.L. (1989). Forecasting, Planning and the future of information society. In Goumain, P. (Ed.), High Technology Workplace: Integrating Technology, Management and Design for the Productive Work Environments (pp. 27-39). New York: Van Nostrand Reinhold. 
Hamre, B., \&Pianta, R. (2007). Learning opportunities in preschool and early elementary classrooms. In R. C. Pianta, M. J. Cox, \& K. L. Snow (Eds.), School readiness and the transition to kindergarten in the era of accountability (pp. 49-83). Baltimore, MD: Paul H. Brookes Publishing

Hijzen, D., Boekaerts, M., \& Vedder P. (2007).Exploring the links between students' engagement in cooperative learning, their goal preferences, and appraisals of instructional conditions in the classroom. Learning and Instruction, 17, 673-687.

Islam, M. (2004) Impact of students' perceptions about teacher interaction and classroom learning environment on attitude towards mathematics and achievement. Ph.D (Doctor of Philosophy) thesis, University of Punjab.

Johnson, D. W., \& Johnson, R. T. (2009).Learning together and alone (5th ed.). Boston, MA: Allyn \& Bacon.

Kim, H. (2000). Classroom environment and teacher interpersonal behaviour in secondary science classes in Korea. Evaluation and Research in Education, $14,3-22$.

Kosir, K., Socan, G., \& Pecjak, S. (2007). The role of interpersonal relationships with peers and with teachers in students' academic achievement. Review of Psychology, 14, 43-58.

Laroque, M. (2008).Assessing Perceptions of the Environment in Elementary Classrooms: the Link with Achievement. Educational Psychology in Practice, 24(4), 289-305. doi:10.1080/02667360802488732

Lippman, P. C. (2007). Can the physical environment have an impact on the learning.

Lujan, J. (1998). How Teacher Behavior Relates To Student Effort In Classrooms For Low And High Status Students. Journal of Applied Behavior Analysis 8 (1975): 341-347.

Luo, M., Huang, W., \&Najjar, L. (2007).The relationship between perceptions of a Chinese high school's ethical climate and students' school performance. Journal of Moral Education, 36, 93-111.

MacLeod, C., \& Fraser, B. J. (2010).Development, validation and application of amodified Arabic translation of the What Is Happening In this Class? (WIHIC) questionnaire. Learning Environments Research, 13, 105-125

Majeed. A., Fraser, B. L \& Aldridge, J. M. (2002). Learning Environment and its Association with satisfaction among mathematics students in Brunei Darrussalam; Learning Environment Research5: 203-226, Doi: 1 0, 1 023/ A, 1020382914724.

Marks, H. (2001). Student engagement in instructional activity: Patterns in the elementary, middle, and high school years. American Educational Research Journal, 37, 153-184. 
Moos, R. H. (1979).Evaluating educational environments. Washington: JosseyBass Publisher.

Parker, J. (2008). Peer relations and later personal adjustment: Are low accepted children at risk? Psychological Bulletin, 102, 357-389.

Pianta, R., Belsky, J., Vandergrift, N., Houts, R., \& Morrison, F. (2008).Classroom effects on children's achievement trajectories in elementary school. American Educational Research Journal, 45, 365-397

Rudasill, K., Gallagher, K., \& White, J. (2010).Temperamental attention and activity, classroom emotional support, and academic achievement in third grade. Journal of School Psychology, 48, 113-134.

Russell, V. J., Ainley, M., \& Frydenberg, E. (2005).Schooling issues digest: Student motivation and engagement. Retrieved November 9, 2005, from http://www.dest.gov.au/ sectors/school education/publications resources/ schooling issues digest/schooling issues digest motivation engagement.htm

Samph, T. (1996).Observer effects on teacher verbal classroom behaviour. Journal of Educational Psychology. 68 (6), pp.736 - 741.

Sandberg, J. A. (1998). Educational paradigms: issues and trends. In Lewis, R. Mendelsohn, P., (ed.), Lessons from Learning, (IFIP TC3/WG3.3 Working Conference 1993), pages 13--22, Amsterdam. North-Holland.

Tanner. C. K. (2000). The influence of school architecture on academic achievement. Journal of Educational Administration, 38, 309-330.

Taylor, P. \& Campbell-Williams, M. (1993). Discourse toward balanced rationality in the high school mathematics classroom: Ideas from Habermas's critical theory. In J.A. Malone \& P.C.S. Taylor (Eds.), Constructivist interpretations of teaching and learning mathematics (Proceeding of Topic Group 10 at the Seventh International Congress on Mathematical Education; pp. 135-148). Perth, Western Australia: Curtin University of Technology.

Wragg, E.C. (2002). An Introduction to Classroom Observation $\left(2^{\text {nd }}\right.$ Ed). Canada: Taylor \& Fransis e-Library.

Zandvliet, D. B. (1999). The physical and psychosocial environment associated with classroom using new information technologies: A cross-national study. Unpublished Ph.D thesis. Curtain University of Technology.

Received on: August 07, 2015

Revised on: January 31, 2016

Accepted on: March 26, 2016 